\title{
Rock no Rio Vermelho: afetos e territorialidades em Salvador
}

\section{Rock in Rio Vermelho: affects and territorialities in Salvador}

\section{Daniel Farias}

Mestrando em Comunicação e Cultura Contemporâneas - PósCom/UFBA, Pesquisador do TRACC.

\section{Jorge Cardoso Filho}

Doutor em Comunicação Social, UFMG. Docente do Centro de Artes, Humanidades e Letras da Universidade Federal do Recôncavo da Bahia.

\section{RESUMO}

Este artigo apresenta e interpreta práticas de rock desenvolvidas em Salvador, no bairro do Rio Vermelho, a partir de uma chave de leitura que articula engajamentos afetivos aos territórios ocupados e apropriados por integrantes da cultura rock. 0 estudo é focalizado em três práticas específicas: o Rock no Vacachorro, evento que ocorreu no Largo de Santana, mais conhecido como Largo da Dinha; o Bate Papo Saco de Vacilo, na casa de show Bardos e Bardos, e o Faça Você Mesma, no Mercadão C.C. São apresentados os afetos que se expressam nessas práticas, as formas de engajamento dos integrantes e construções de territorialidades diversas no bairro do Rio Vermelho. 


\section{ABSTRACT}

This article presents and interprets rock practices developed in Salvador, in the Rio Vermelho neighborhood, from a perspective that articulates affective engagements to the territories occupied and appropriated by members of rock culture. The study focuses on three specific practices: Rock no Vacachorro, an event that took place at Largo de Santana, better known as Largo da Dinha; Bate Papo Saco de Vacilo, at the Bardos e Bardos concert hall, and Faça Você Mesma, at Mercadão C.C. The affections that are expressed in these practices, the forms of engagement of the members and the construction of different territorialities in the Rio Vermelho neighborhood are presented as conclusions.

KEYWORDS: Rock; Salvador; Territory; Rio Vermelho.

\section{RESUMEN}

Este artículo presenta e interpreta algunas prácticas de rock desarrolladas en Salvador, en el barrio de Rio Vermelho, a partir de un código de lectura que articula compromisos afectivos con los territorios ocupados y apropiados por miembros de la cultura del rock. El estudio se centra en tres prácticas específicas: Rock no Vacachorro, un evento realizado en Largo de Santana, más conocido como Largo da Dinha; Bate Papo Saco de Vacilo, en la sala de conciertos Bardos e Bardos, y Faça Você Mesma, en Mercadão C.C. Se presenta el afecto expresado en estas prácticas, las formas de compromiso de los miembros y la construcción de diferentes territorialidades en el barrio de Rio Vermelho.

PALABRAS-CLAVE: Rock; Salvador; Territorio; Rio Vermelho

\section{Introdução}

As relações entre música e cidade configuram uma multiplicidade de práticas que podem ser reveladoras das diferentes maneiras de viver, perceber e disputar os seus territórios. Abarcam as particularidades dos espaços públicos, dos tipos de ocupação e imaginários que coexistem e são continuamente (re)construídos. No bairro do Rio Vermelho, localizado na Orla Atlântica da cidade de Salvador, as práticas de rock são cultivadas há pelo menos duas décadas, tendo as casas de show, sobretudo, como um dos seus principais espaços de expressão. Difícil encontrar um fã de rock soteropolitano que não passou pelo (ou, ao menos, ouviu falar do) Calypso, Idearium ou Irish Pub, inferninhos que tinham na sua programação, com recorrência, shows de bandas associadas ao gênero. Além desses espaços, as ruas e praças são ocupadas por artistas e 
fãs de rock em rodas de violão e gambiarras com equipamentos de som que possibilitam às bandas a realização de suas apresentações.

De modo amplo, a música é um elemento fundamental nesse bairro ${ }^{1}$ da capital baiana, que, em 2015, recebeu o controverso título City of Music da Unesco². Diversos gêneros e territorialidades sônico-musicais (Herschmann, 2013) convivem - não sem tensões - nessas ruas, em locais privados, nas playlists dos botecos e nos sons de aparelhagens instaladas em malas de carros. Dessa maneira, alianças afetivas (Grossberg, 1997) relacionadas à música e ao bairro são produzidas, evidenciando também processos de apropriação e produção da cidade, que agregam valores e visões de mundo.

Em relação ao rock, mesmo em um momento histórico no qual há presença recorrente de discursos, mormente na imprensa e em sites de redes sociais online, que sentenciam o seu suposto conservadorismo, um declínio comercial e, no limite, a sua morte, os eventos roqueiros ainda constituem uma parte significativa dos eventos no bairro, tanto nas casas de show como em eventos e festivais na rua. Ao mesmo tempo, tais práticas evidenciam disputas e negociações, por meio dos afetos articulados ao rock, sobre os seus espaços que envolvem territorialidades e os modos de controle territorial, principalmente pela Prefeitura de Salvador com a reforma planejada e executada no Rio Vermelho entre 2014 e 2016.

\footnotetext{
${ }^{1}$ Relacionado à vida boêmia e noturna, o Rio Vermelho apresenta dinâmicas residenciais e comerciais, ao mesmo tempo em que recebe turistas em seus hotéis, restaurantes e pontos específicos, como a escultura de Jorge Amado e Zélia Gatai, a Casa do Rio Vermelho e, mais recentemente, a Vila Caramuru. Anualmente, no dia 2 de fevereiro, ocorre a festa de Iemanjá, que homenageia a Orixá reverenciada em religiões de matrizes africanas e associada à cultura popular soteropolitana.

${ }^{2} \mathrm{O}$ título City of Music (Cidade da Música), concedido a Salvador pela Organização das Nações Unidas para a Educação, a Ciência e a Cultura (Unesco), se configura como uma modalidade ou selo das cidades criativas, que, por sua vez, se inserem, em geral, em uma perspectiva neoliberal e/ou neodesenvolvimentista (Fernandes \& Herschmann, 2018). Na descrição de Salvador no site oficial do projeto, fica evidente, em trechos variados, tais perspectivas: "Salvador é mais conhecida por seu carnaval. [...] Estima-se que esse grande evento represente mais de US\$ 248 milhões em transações financeiras. [...] o carnaval baiano tem sido responsável por promover a indústria musical local em escala internacional, com um aumento [...] de parcerias multiníveis, tal como oportunidades de emprego. A cidade, na qual a economia criativa envolve diretamente o setor musical, colocou a música no centro dos seus planos de desenvolvimento social e econômico" (CITY OF MUSIC, tradução nossa). Disponível em: <https://citiesofmusic.net/city/salvador/>. Acesso em: julho de 2019.
} 
Assim, este artigo analisa como práticas de rock ${ }^{3}$, em espaços públicos e casas de show - especificamente o Rock no Vacachorro, evento que ocorreu durante alguns anos no Largo de Santana, mais conhecido como Largo da Dinha; o Bate Papo Saco de Vacilo, na casa de show Bardos e Bardos, e o Faça Você Mesma, no Mercadão C.C. -, expressam afetos, engajamentos e a construção de territorialidades no bairro do Rio Vermelho. Nesse sentido, articula-se a perspectiva de Lawrence Grossberg $(2010,2018)$ acerca dos afetos - enquanto modos de engajamento construídos e organizados nas práticas discursivas e culturais - às compreensões do poder e das formações discursivas do filósofo Michel Foucault.

Propõe-se uma compreensão das práticas de rock a partir dos territórios como eixos afetivos, discutindo os engajamentos e as territorialidades (Haesbaert, 2014) manifestadas em discursos e valores relacionados aos eventos no bairro. Os modos de ocupação desses espaços são observados em discursos de artistas, frequentadores, produtores e jornalistas ${ }^{4}$ em produções audiovisuais, nas páginas dos eventos em sites de redes sociais online e em matérias que se reportam ao bairro publicadas em sites e blogs de rock entre 2014 e 2019 (período em que se intensificaram algumas mudanças nos espaços, a partir das citadas intervenções da prefeitura de Salvador).

Assim, as discussões desenvolvidas enfrentam duas questões centrais. A primeira é específica e relacionada às experiências, afetos e disputas espaciais do rock em Salvador, frente a processos de territorialização mais fechados, redutores e/ou voltados

\footnotetext{
${ }^{3}$ Entende-se as práticas associadas ao rock (ou práticas roqueiras) como os modos de comportamento (Grossberg, 1986) relacionados ao gênero e às suas convenções, envolvendo discursos, sonoridades, locais de show, performances, posições políticas.

${ }^{4}$ Por exemplo, o cantor e compositor soteropolitano Giovani Cidreira, ex-integrante da banda de rock Velotroz, em entrevista a Farias (2017) publicada no site El Cabong, defendeu: "Hoje não vejo o rock puro como uma coisa a ser considerada. Não vejo nada de bom há algum tempo. É uma coisa que já passou. Rock para mim está mais ligado à postura. Sempre esteve, na verdade. [...] Os roqueiros que eu vejo atualmente [...] são muito conservadores.". Tal declaração gerou uma extensa discussão no perfil do artista no Facebook e em outros perfis e páginas ligadas ao rock na cidade. Já o artista Eldo Luiz, que fez parte da banda de metal Dynamus e depois seguiu trabalho solo no rap, afirmou em entrevista ao site Rock Loco: "O rap é um elemento de rua, do ao vivo, das vivências urbanas, algo muito próximo do hardcore e do thrash metal, [...] minhas escolas. O rock está ficando cada vez mais conservador e enfadonho no Brasil". Essas e outras definições têm sido recorrentes nas discussões sobre o gênero musical; há, porém, também discursos e práticas que se se contrapõem a essa redução: ao citar o evento Faça Você Mesma, um dos objetos de análise deste artigo, na programação do Festival Bigbands, o produtor Rogério BigBross diz o seguinte: "o Faça você mesma veio realmente num momento especial. 0 rock e o metal vem sendo tachado de conservador, quando sugeri esse dia aos coletivos Mosh like a girl e Crust or die label and collective foi pra dizer: 'Peraí, tem gente de todo tipo. Não bota todo mundo no mesmo bolo, não!'”. Disponível em: $<$ www.elcabong.com.br/entrevista-giovani-cidreira-e-seu-universoparticular>;<www.rockloco.blogspot.com/2019/05/do-metalcore-ao-rap.html>; <www.rockloco.blogspot.com/2018/11/bigbands-big-shows.html>. Acesso em: junho de 2019.
} 
para disciplina e o controle. Já a segunda, situada também num nível mais amplo, está direcionada aos reiterados discursos ${ }^{5}$ que enquadram o rock como conservador.

\section{Rock RV: tensões e disputas}

As conexões entre o rock e o Rio Vermelho incorporaram (e ainda incorporam) disputas diversas em torno da música na capital baiana. Entretanto, os tensionamentos geralmente eram focalizados na oposição entre rock e axé-music, o primeiro visto como autêntico e o segundo como cooptado. Nos caminhos trilhados aqui, busca-se ampliar tal entendimento, considerando nuances sobre a música e a cidade e questões que envolvem modos de ocupação dos espaços urbanos, afetos, valores e relações de poder.

Para expor um exemplo emblemático desse enquadramento, a música “Controle total”, da banda Camisa de Vênus ${ }^{6}$, tem em seus versos: “[...] Aqui em Salvador / a cidade do axé, a cidade do terror [...] Mas se quiser tentar / Tem fitinhas do Bonfim, acarajé e abará / Essa é a grande senha: Oxum, Badauê e Zanzibar / Tá tudo armado, para lhe imobilizar". Ou seja, esse movimento oposicional do rock se dirigia tanto à indústria do Carnaval e ao axé-music, quanto a elementos da cultura local que dialogam com matrizes carnavalescas e afro-baianas.

Como sublinha Janotti Júnior em pesquisa sobre o rock pesado em Salvador entre o final dos anos 1990 e a primeira metade dos 2000, "assumir-se headbanger [fã de heavy metal ou seus subgêneros] [...] é, antes de tudo, operacionalizar valores diferenciais à axé-music [...] não só em relação ao turismo nacional, como internacional". No entanto, ao discutir os confrontos entre o que intitula de "cena roqueira" e a música de Carnaval, ele cita o Acarajé da Dinha, no Rio Vermelho, enquanto espaço em que "dendê e heavy metal se misturam", indicando que pontos de encontro de fãs de rock, amiúde, atravessam a “cidade tradicional e suas recriações” (Janotti Júnior, 2004, p. 57).

\footnotetext{
${ }^{5} \mathrm{O}$ debate sobre o suposto conservadorismo no rock não é novo (Grossberg, 1986), embora, em alguns espaços e momentos históricos, tenha diferentes enquadramentos e atualizações. Com a ascensão da extrema-direita no Brasil e a auto-afirmação da identificação com a direita e a defesa do conservadorismo por artistas ligados ao rock como Lobão e Roger, esse debate adquire um novo fôlego nos últimos anos, sobretudo em discursos em matérias e listas na imprensa. Disponível em: <www. oglobo.globo.com/lobao-volta-com-disco-de-ineditas-diz-todo-roqueiro-conservador-18131776>; $<$ www.gazetadopovo.com.br/caderno-g/musica/de-elvis-presley-a-lobao-conheca-seis-roqueiros-dedireita-c4kstnjfbouls578d2hib3e9y/>. Acesso: julho de 2019.

${ }^{6}$ Uma das principais bandas de rock de Salvador em termos de projeção nacional e visibilidade, criada em 1980 e ainda em atividade. 0 seu álbum Viva, lançado em 1986, vendeu cerca de 180 mil cópias.
} 
Ou seja, apesar das diferenciações afetivas colocadas, as práticas roqueiras no bairro envolvem certas negociações. Outros autores, em abordagens distintas, também tratam dessa oposição e de seus diálogos, ora evidenciando aspectos reivindicados pela crítica cultural (Cardoso Filho, 2018), ora certas aproximações no vetor de direção do axémusic (ou "música afro-pop baiana") para o rock (Guerreiro, 2000).

Nos últimos anos, em que a indústria do axé-music, ou o chamado Carnavalnegócio (Miguez, 2008), vem perdendo força na capital baiana, existem reconfigurações e deslocamentos de foco desses confrontos do rock. Contudo, os diálogos e enfrentamentos demonstram que há diferentes relações das práticas do rock com o Rio Vermelho - como território afetivo de disputas, negociações, confrontos de valores e criação de imaginários - que são cultivadas no tempo.

A vinculação entre o rock e o bairro também entrecruza desigualdades sociais e territoriais. A maior parte dos shows deste gênero musical continua ocorrendo em espaços privados no Rio Vermelho, o que acaba sendo um limite para a presença frequente de moradores de bairros afastados nesses eventos, principalmente pelas dificuldades de mobilidade, embora também seja um fator central acionado e, ao mesmo tempo, motivador para a ocupação de espaços e criação de casas de show em outros lugares ${ }^{7}$.

Já em relação às tensões sobre os espaços públicos, destaca-se que a grande reforma planejada e executada no bairro pela prefeitura de Salvador entre 2014 e 2016 gerou questionamentos de frequentadores sobre aspectos que vão do aumento do "custo de bens e serviços", "a estética de resort"8, a "cara de shopping center"9 e a prioridade

\footnotetext{
${ }^{7}$ No perfil do Bukowski Porão Bar (estabelecimento voltado para o rock situado no Pelourinho) publicado na Revista Muito do jornal $A$ Tarde, destaca-se que "o lugar surgiu como uma opção underground no centro, já que todos os eventos do gênero costumavam acontecer no Rio Vermelho". Já na matéria sobre o Espaço Cultural Dona Neuza, no Marback, o administrador do bar, Lindomar Luís, diz que "tem muita coisa [...] fora do circuito mais conhecido. Sempre pensamos o Espaço Cultural Dona Neuza como uma opção fora do Rio Vermelho. Nada contra o que é feito por lá, mas o circuito é bem maior". Disponível em: <www.atarde.uol.com.br/muito/noticias/1835171-cronica-de-um-bar-louco>; atarde.uol.com.br/muito/noticias/som-de-casa-1618670>. Acesso em: junho de 2019.

${ }^{8}$ Disponível em: <www.atarde.uol.com.br/muito/noticias/1732872>. Acesso em: junho de 2019.

${ }^{9} \mathrm{Em}$ texto sobre uma noite de rock no Rio Vermelho, no blog Soterockpolitano, o fã e jornalista Leo Cima fala sobre a reforma em andamento no bairro: "A obra da prefeitura para revitalizar o local deixou o espaço mais apertado para os seus frequentadores [...] É muito provável que o local fique bem parecido com a Barra depois da sua reforma, ou seja, a cidade vai ficando aos poucos com cara de shopping center e perdendo as suas peculiaridades [...] que cada bairro tem". Daqui a pouco estaremos em um não-lugar." (CIMA, 2015). Disponível em: <http://www.soterorockpolitano.com/2017/03/a-cena-vai-bemobrigado.html>. Acesso em: junho de 2019.
} 
dada ao turismo, até a ausência de debate coletivo para a intervenção. Critica-se, sobretudo, a tentativa de controlar ${ }^{10}$ um espaço marcado pela diversidade, que inclui shows de rock nas suas ruas e praças.

\section{Afetos e territorialidades: reflexões sobre discursos, engajamentos e aberturas}

Em suas reflexões acerca dos afetos, Lawrence Grossberg assinala que, frequentemente, "supõe-se que o afeto é mais natural do que construído e, com frequência, que é necessariamente desorganizado (em oposição, por exemplo, à linguagem)" (2010, p. 193, tradução nossa). O autor questiona essa linha de raciocínio ao argumentar que a produção dos afetos nunca foi aleatória: o "afeto é sempre organizado por aparatos discursivos e culturais, que são, por sua vez, locais/agentes da produção do real e da luta em torno dele, na forma de hábitos e costumes" (2010, p. 194, tradução nossa). É no nível cotidiano, que abarca as culturas, as comunicabilidades, as sensibilidades e as práticas políticas, que os afetos se manifestam como investimentos, configurando o que ele intitula como mapas de importância.

Essas produções e organizações afetivas englobam valores, modos de vida, humores, paixões, posições - ou seja, um conjunto complexo no qual o particular interfere e diz de um todo ou de um coletivo em constante movimento. Segundo Grossberg, o afeto é

[...] uma dimensão ou ingrediente essencial das desordens da experiência humana [...] Como plano do significado, o afeto é o produto contingente de eventos, contradições e lutas humanas e não humanas. Varia ao longo do tempo e do local e é distribuído de forma desigual [...]. Se o significado é como fazemos "sentido" com o que está acontecendo, afeto é a energia que permeia todas as nossas experiências e define como é viver em um momento. [...] o afeto é sempre constituído no espaço entre individualidade e socialidade, entre consciência e materialidade, entre o cognoscível e o ainda nãoarticulado [...] engloba uma variedade de maneiras pelas quais "sentimos" o mundo [...] incluindo humores, emoções, mapas do que importa e do que se importa, prazeres, desejos, paixões, sentimentos. (GROSSBERG, 2018, p. 10 e 11).

Embora dotada de uma amplitude que permite diferentes entradas e aproximações, tal perspectiva dos afetos também demanda uma articulação

10 Uma consequência quase imediata à inauguração da obra foi a diminuição do número de vendedores informais nas imediações dos principais largos. A responsabilidade de algumas dessas ações ficou a cargo da Secretaria Municipal de Ordem Pública, que, pelo próprio nome, já denota o caráter ordenador dos espaços públicos. 
metodológica que tome os discursos enquanto materialidade dos sentidos pela linguagem e como enunciados e práticas que contribuem na apreensão e mapeamento dos seus vetores e dinâmicas como processos ativos. $\mathrm{Ou}$, formulando a questão de outro modo, como os discursos contribuem para pensar e analisar as práticas afetivas e os engajamentos na música, especialmente no rock? E como se conectam ao bairro do Rio Vermelho, em Salvador?

Em $A$ arqueologia do saber, Foucault (1987) reflete sobre o conhecimento, a história e os discursos, entre outros temas, e desenvolve mais direta e detalhadamente o seu pensamento sobre as regularidades, descontinuidades e possíveis transformações discursivas. Faz isso através do conceito de formação discursiva, chave no seu trabalho teórico, metodológico e nas suas análises.

No caso em que se puder descrever, entre [...] enunciados, semelhante sistema de dispersão, e no caso em que entre os objetos, os tipos de enunciação, os conceitos, as escolhas temáticas, se puder definir uma regularidade (uma ordem, correlações, posições e funcionamentos, transformações), diremos [...] que se trata de uma formação discursiva (FOUCAULT, 1987, p. 43).

Nos sistemas de rarefação e dispersão dos enunciados, a noção de formação discursiva convoca o olhar para as regularidades na produção de um conjunto, tanto aquelas reforçadoras de relações de poder dominantes, como para as rupturas, aquilo que questiona um regime de verdade, seja no que é dito, seja por meio do que (ainda) não foi expresso e (ainda) persiste no silêncio. Ou seja, há as reiterações, regularidades, mas também podem existir outros enunciados que produzem descontinuidades, abrindo caminho para a construção de outras formações sobre o mesmo objeto.

Desse modo, é possível pensar em formações discursivas que envolvem imaginários (ou regimes de verdade) acerca das cidades relacionados à música, a exemplo de Salvador como cidade da alegria, da felicidade e do axé-music, ou Rio de Janeiro enquanto como capital da bossa nova e do samba. Tais construções articulam afetos direcionados aos territórios, uma vez que envolvem configurações do poder, desde lógicas predominantemente econômicas no espaço urbano, como o turismo, até as matrizes culturais.

Para Jason Mittell as formações discursivas são "sistemas de pensamento historicamente específicos [...] que trabalham para definir experiências culturais dentro 
de grandes sistemas de poder" (Mittell, 2001, p. 9). Assim, desenvolve que tais discursos são mais bem examinados a partir das suas "enunciações de superfície, em vez de serem interpretados e 'lidos' como textos de mídia", na medida em que atuam na produção de contextos, práticas e relações culturais, sensíveis e políticas. Enquanto parte fundamental da vida cotidiana, os afetos, manifestados em formações discursivas, implicam tanto as estruturações, conformações e práticas do poder (presente, na acepção de Foucault (2014), em múltiplas escalas e esferas) como os investimentos e engajamentos articulados aos espaços urbanos. Nesse sentido, os afetos também são constituídos a partir das relações estabelecidas com territórios.

Já a noção de territorialidade, embora não seja um elemento abstrato do território, “é também uma dimensão imaterial [...] enquanto 'imagem' ou símbolo de um território, [...], e pode inserir-se eficazmente como uma estratégia político-cultural" (Haesbaert, 2014, p. 64). Ou seja, por meio de formações discursivas, modos de ocupação da cidade e produções audiovisuais sobre certos espaços, são construídas continuamente territorialidades (em discursos, imaginários, significados), ora podendo reforçar lógicas dominantes e/ou fechadas em um território, ora amplificando as suas possibilidades de abertura para a diversidade dos investimentos afetivos e dos modos de vida. Assim, se as territorialidades são, sincrônica e diacronicamente, múltiplas (o que convoca a ideia de multiterritorialidades), uma questão central é perceber como os afetos estão operando na produção de territórios mais abertos e contingentes - sem recair em generalizações, relativismos e/ou essencialismos - que podem funcionar como eixos capazes de gerar engajamentos e processos de empoderamento estratégico e transformação.

O território [...] é o contexto da realidade vivida. Descreve uma realidade afetiva, ou melhor, um complexo conjunto de articulações e registros afetivos que constituem diferentes modos de viver em locais já socialmente determinados, diferentes possibilidades de formas e configurações de investimento, colocação e orientação, mudança e segurança, atenção e importância, prazer, desejo e emoções. Estabelece relações complicadas entre pertencimento e alienação, identidade e identificação, subjetivação e assujeitamento. (GROSSBERG, 2010, p. 34, tradução nossa)

Considerando os territórios como eixos afetivos que são disputados por meio de enunciados que deixam ver formações discursivas, volta-se o olhar para as postagens, flyers, vídeos, matérias, resenhas, críticas e reportagens sobre práticas de rock 
desenvolvidas no Rio Vermelho, no período delimitado entre 2014 e 2019. A escolha dos projetos e eventos - Rock no Vacachorro, Bate Papo do Saco de Vacilo e Faça Você Mesma - foi feita com base em um mapeamento prévio de práticas rock no bairro e levando em conta aquelas que constroem algum grau de resistência e promovem alianças afetivas que colocam em foco e/ou tensionam relações de poder, como desigualdades sociais e territoriais, sexismo e tentativas de disciplinarização e controle dos territórios.

Nos engajamentos afetivos que interligam rock e territórios em Salvador, percebidos ao longo do tempo, identificou-se tanto discursos sobre o seu lugar histórico de oposição à indústria do axé-music e, junto com isso, à imagem da cidade e a sua leitura idílica de "terra da alegria e da felicidade" enquanto construção orientada para o desenvolvimento turístico da cidade, quanto aproximações com esse imaginário relacionado à capital baiana. Nesse quadro, o bairro do Rio Vermelho aparece como um importante espaço de investimentos afetivos e engajamentos sobre questões territoriais e identitárias na cidade, não mais necessariamente articuladas ao axé-music e à sua indústria.

São analisadas, então, como algumas práticas roqueiras de ocupação de espaços no Rio Vermelho deixam ver limites e potencialidades em processos de produção de territorialidades, contribuindo para a (des)estabilização de lógicas de enquadramento e controle territorial, tal como a formação discursiva de que o rock teria se tornado um gênero musical conservador. Dessa maneira, demonstra-se que os territórios e a construção de territorialidades (Haesbaert, 2014), a partir de alianças e vínculos no Rio Vermelho, se configuram como eixos afetivos do rock em Salvador, mobilizam engajamentos e podem tensionar e instabilizar lógicas urbanas restritivas, fechadas, voltadas para a disciplina e o controle espacial, ao ocupar o espaço público com música em função de um engajamento afetivo político, e não somente como uma reação à falta de espaços. Assim, é possível descolonizar a noção generalizada de um conservadorismo que é associado ao rock, expondo também questionamentos de desigualdades sociais, territoriais e práticas misóginas.

\section{Ocupação da rua e valores em tensionamento: o rock do Vacachorro}


O Vacachorro, escultura feita por Bel Borba11 que, entre 2010 e 2015, ficava localizada no Largo de Santana, é um dos espaços no qual, a partir da sua ocupação e a própria nomeação por frequentadores, é possível mapear e analisar engajamentos afetivos e territorialidades associadas ao rock no Rio Vermelho. 0 nome se deve à pintura em preto e branco ostentada durante um período pela escultura, que remetia a uma vaca com corpo de cachorro.

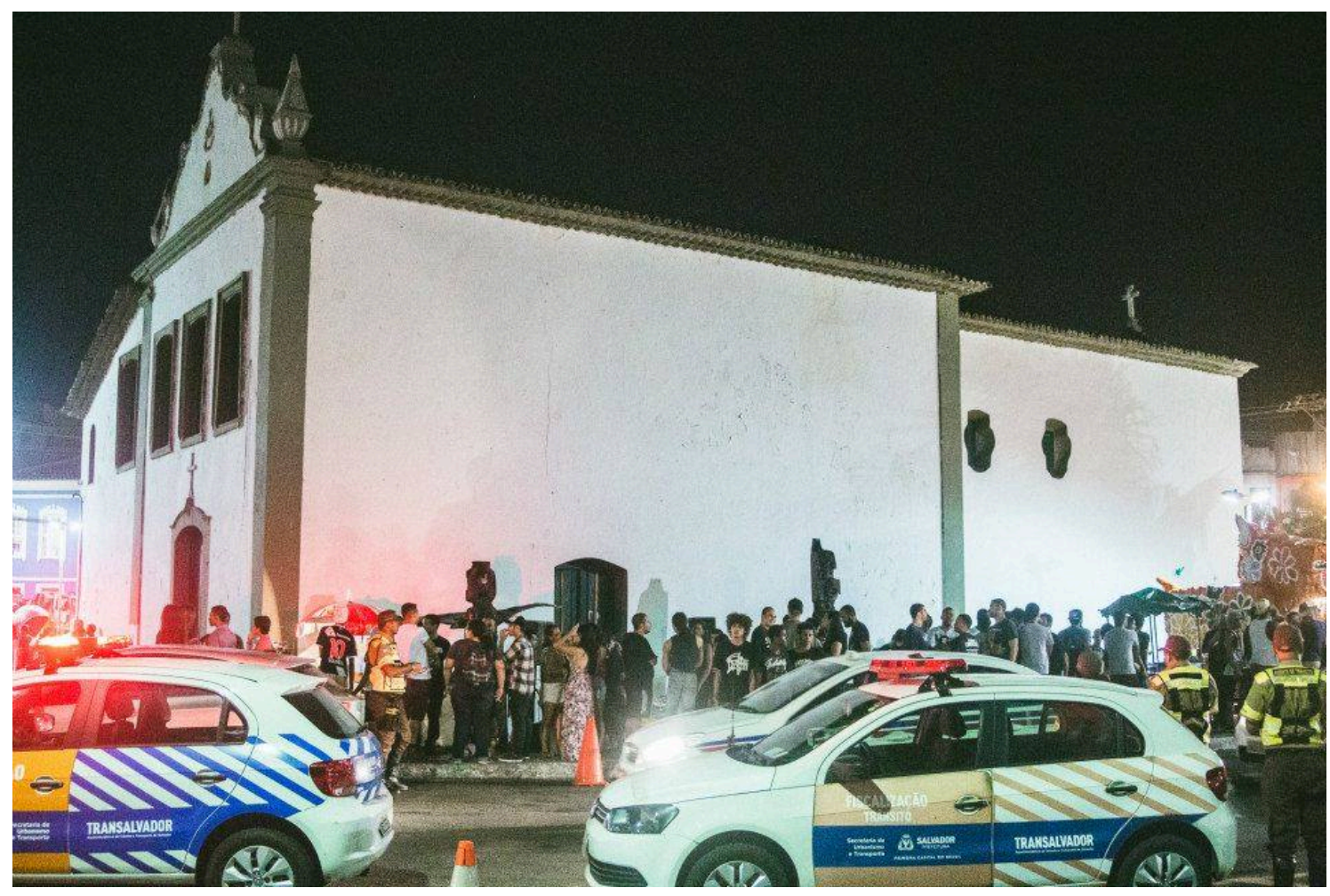

${ }^{11}$ Artista plástico de Salvador, com obras (esculturas, mosaicos) em diversos espaços públicos da cidade. 

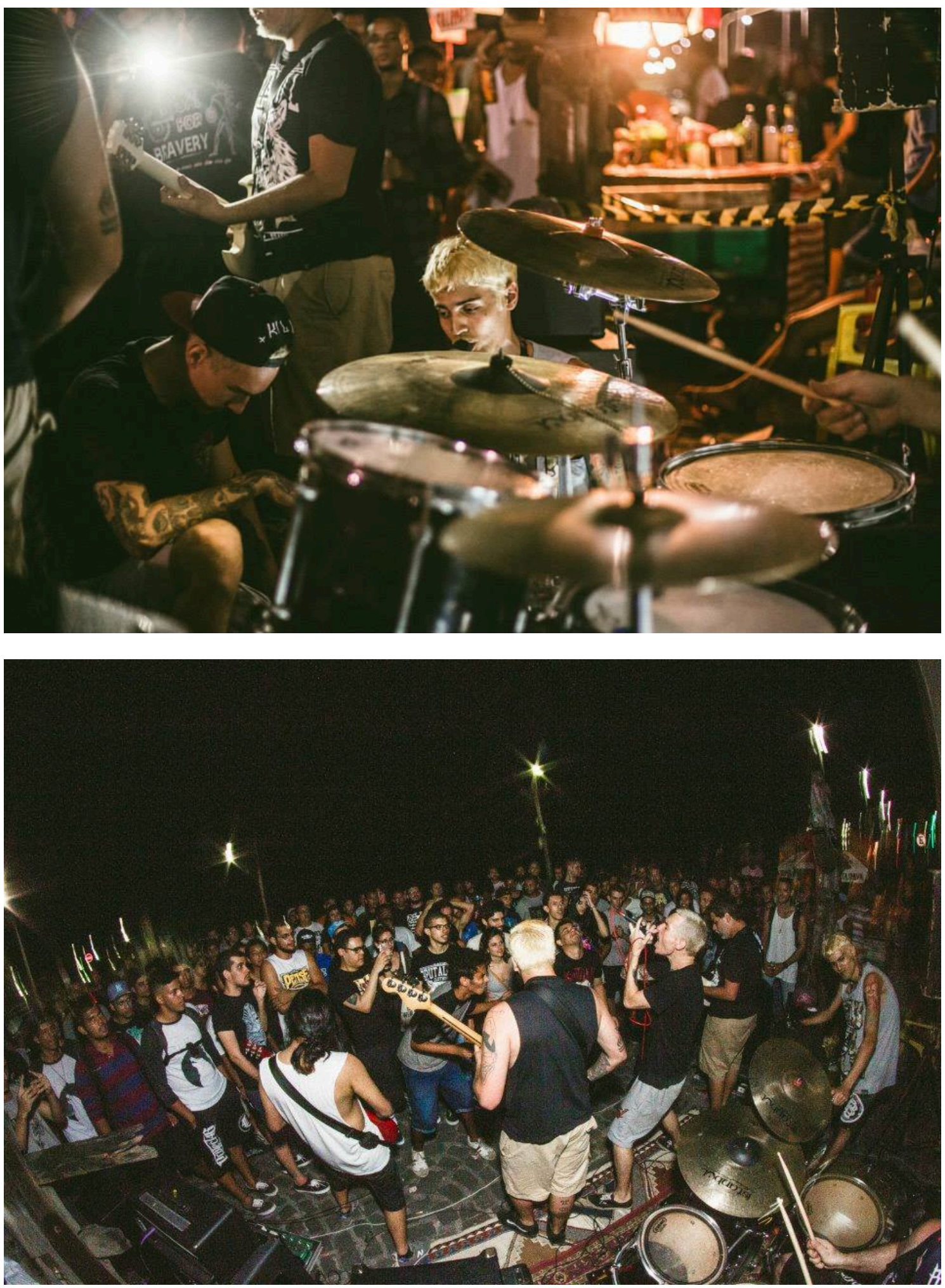

Imagens do evento Bullet Blane em Salvador; ao fundo, a barraca de Príncipe Maluco; Transalvador tenta controlar o trânsito no espaço ${ }^{12}$. Fotos de Tinho Sousa

${ }^{12}$ Disponível em: <www.facebook.com/events/857656217601019>. Acesso em: junho de 2019.

Dossiê Espaço Urbano e Imaginação Cultural - https://revistaecopos.eco.ufrj.br/

ISSN 2175-8689 - v. 22, n. 3, 2019.

DOI: 10.29146/eco-pos.v22i3.27410 
Inicialmente, o seu entorno era um local em que jovens, parte significativa dos quais eram roqueiros, se reuniam ao lado de uma barraca de Príncipe Maluco, bebida vendida em festas populares da capital baiana, como o carnaval e as festas de largo. Os encontros, espontâneos ou agendados por meio de grupos em plataformas de redes sociais online, foram se tornando cada vez maiores em número de pessoas. Assim, shows começaram a acontecer, viabilizados pela utilização da energia elétrica da barraca de bebidas. Diversas vezes, a Transalvador ${ }^{13}$ era mobilizada para interferir no trânsito na região.

Os eventos não tinham autorização prévia da prefeitura, fato que gerava tensões sobre um possível impedimento da realização das apresentações, como já havia ocorrido até mesmo em espaços privados, que supostamente estavam ultrapassando o limite de altura do som e/ou não tinham alvará de permissão dos órgãos municipais.

As maneiras de ocupação desse espaço evidenciam alguns engajamentos afetivos e construções de territorialidades, tal como valores relacionados ao rock e ao bairro do Rio Vermelho. Em primeiro lugar, a própria presença de jovens vestidos predominantemente de preto e reunidos à noite, pulando, dançando e participando das eventuais rodas de pogo ${ }^{14}$, em shows gratuitos e na rua, com palco horizontal (e muitas vezes sem palco, quando o público e a banda se misturavam) já deixa ver tensionamentos territoriais afetivos sobre uma lógica de organização do Rio Vermelho enquanto espaço ordenado, turístico e boêmio (pelo consumo, sobretudo, nas mesas dos bares, casas de show ou boates).

Nesse sentido, a ocupação e as performances de rock no Vacachorro podem ser entendidas a partir do que Foucault define como heterotopias, espaços da transitoriedade, temporários. Espaços que, nos termos do próprio autor, justapõem "em um lugar real vários espaços que, normalmente seriam ou deveriam ser incompatíveis" (2013, p. 25).

$\mathrm{Na}$ divulgação do show das bandas BulletBane, de São Paulo, e das soteropolitanas Buster e Callifornians Covers, e na página Coisa que Ovelha15, ambos no

\footnotetext{
${ }^{13}$ Autarquia da Prefeitura de Salvador cujo objetivo é a gestão do trânsito e dos estacionamentos na cidade.

${ }^{14} \mathrm{~A}$ roda de pogo ou roda punk é uma performance, comum em shows de rock, em que os fãs formam uma roda, estabelecendo contatos corporais, empurrões e encenando socos e chutes.

15 Disponível em: <www.facebook.com/events/857656217601019/>; <www.facebook.com/CoisaQueOvelha/>. Acesso em: junho de 2019.
} 
Facebook, as descrições do evento no Vacachorro, em 2014, destacaram a realização na rua e aberta ao público. Já os nomes das bandas, em língua inglesa, realçam uma dimensão internacionalizada ${ }^{16}$ do rock no bairro. Além disso, reivindica-se o caráter colaborativo e o valor17 "do it yourself" associado ao rock, sobretudo ao punk. No discurso de um dos músicos e produtores do evento, percebe-se tais vetores afetivos: “[...] a intenção era fazer [...] em um local fechado. Mas a gente não conseguiu por conta da falta de um local, [...] Salvador está precária de espaços [...] E aí surgiram pessoas que tornaram possível [...] fazer a parada acontecer" (Jhonny, 2014).

As demandas por mais casas de shows e pela possibilidade de realizar apresentações nesses locais privados é colocada em primeiro plano no discurso do produtor e artista18. Desde o final dos anos 1990 e início dos 2000, os eventos nas casas de shows e bares são vistos como fundamentais (ou mesmo condição) para a continuidade da cena de rock pesado.

Embora haja uma potência no discurso do músico e produtor para a construção de territórios e territorialidades em rede com a ocupação do Vacachorro, que articula artistas, produtores e fãs em colaborações (na produção, no empréstimo de equipamentos de som, auxílio dos trabalhadores informais com a energia elétrica) e modos de divulgação (eventos online, convites para amigos em comum), o motivo apresentado pelo produtor para a realização do show naquele espaço recorre ao velho argumento, com suas eventuais renovações, sobre a falta de locais privados.

Levando em conta tal perspectiva, reflete-se sobre a própria ocupação musical da rua como uma maneira de instabilizar formações discursivas sobre o Rio Vermelho, evidenciadas pela prefeitura, em que predominam noções de bairro turístico e comercial. Além disso, há disputas, a partir da ocupação do Vacachorro em encontros e

\footnotetext{
${ }^{16}$ Essas ligações mais ou menos internacionalizadas, segundo Janotti Júnior (2001, p. 2), podem ocorrer de acordo com os investimentos afetivos e diferenciações a partir do acionamento de elementos regionais, de uma certa raiz local, ou mundializados.

${ }^{17}$ Como destaca ainda Janotti Júnior (2001, p. 6), muitas das escolhas "operadas ao redor dos gêneros musicais são calcadas em julgamentos de valor".

${ }^{18}$ Na matéria "Rock no Vacachorro", publicada no blog Soterorockpolitano, o editor Leo Cima, após ir para o evento Show Colaborativo, no Vacachorro, trata das apresentações das bandas, cita que o integrante de um dos grupos estava com o boné da casa de shows Nhô Caldos, onde aconteciam apresentações de rock, e, no final do texto, afirma: "Na volta para casa, fui pensando [...] sobre esse evento. Acho válida a iniciativa e o gesto de fazer acontecer a música que você acredita, mesmo que seja no meio da rua e acho que isso acontecerá mais vezes. Mas por quanto tempo esses artistas terão que se expressar dessa forma? Esse evento também expõe uma das precariedades da nossa cena local, que é a falta de casas voltadas para esse tipo de som.". Disponível em: <http://www.soterorockpolitano.com/2017/03/rock-no-vacachorro.html>. Acesso em: 21 de maio de 2019.
} 
show de rock, que tensionam uma territorialização mais funcional através da tentativa de controle do espaço pela prefeitura, como revelam as imagens da Transalvador ao lado do evento. Isso se torna ainda mais evidente no período de execução da reforma no bairro, quando a própria escultura, ou territorialidade afetiva roqueira no Rio Vermelho, foi removida pela prefeitura. Mesmo depois do término da intervenção, a obra não foi recolocada no largo.

Em postagem ${ }^{19}$ em sua página no Facebook, após a reforma, a prefeitura apresenta uma imagem do Vacachorro não mais em seu local de origem, na divulgação do evento de inauguração da "Nova Orla" do Rio Vermelho. O cenário da imagem também não é mais a noite e o show de rock, mas trabalhadores dando os "toques finais" na escultura em um dia ensolarado, o que revela uma disputa que associa o Vacachorro, território afetivo já cultivado por frequentadores, a outras territorialidades - em outro largo (que serve mais como estacionamento durante a noite) e ligado ao show promovido pela prefeitura "com a presença de grandes artistas da música baiana [...] uma homenagem a Iemanjá", como aparece na nota oficial20. Contudo, na mesma publicação, seguidores destacam a relação entre a escultura e "aquele rock de rua", e que a reforma foi realizada "sem diálogo com a população" e significa uma "elitização total do bairro, construindo uma cidade mais segmentada e desigual, a favor da gentrificação". Ou seja, tais afetos e valores são disputados na própria página da prefeitura.

\footnotetext{
${ }^{19}$ Disponível em: <www.facebook.com/prefeituradesalvador/photos/a.476975768984741/1292259414123035>. Acesso em: junho de 2019.

20 Disponível em: <http://www.agenciadenoticias.salvador.ba.gov.br/index.php/pt-br/releases2/geral/3058-prefeitura-entrega-nova-orla-do-rio-vermelho-na-sexta-29-com-grande-festa>. Acesso em: junho de 2019.
} 

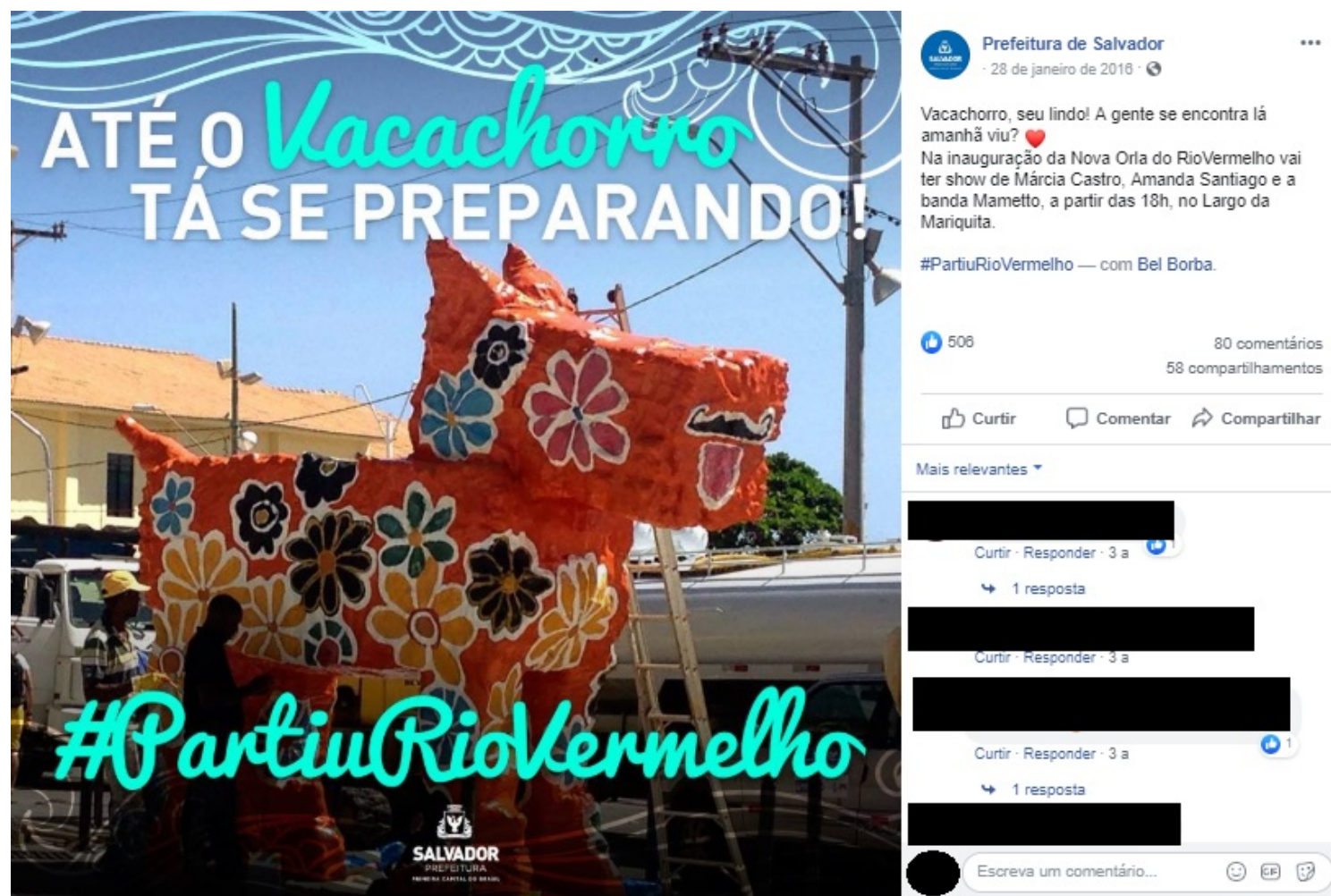

Postagem na página da Prefeitura de Salvador no Facebook.

Ficam evidentes, nos engajamentos roqueiros relacionados ao Vacachorro, oscilações entre a ocupação como alternativa à falta de espaços para shows e tensionamentos a partir da realização de eventos nesse espaço público com um tipo de reterritorialização da prefeitura que privilegia um discurso ordenador, turístico e comercial do bairro - que inclui a remoção e uma certa apropriação do Vacachorro em sua propaganda institucional. Paralelamente, destacam-se os deslocamentos e as territorialidades mais abertas, diversas e transitórias através das disputas em torno do Vacachorro. Ressalta-se, nesse processo, que é necessário considerar uma dimensão mais ampla que se abre ao articular engajamentos e territorialidades afetivas nesses deslocamentos, sejam eles discursivos, simbólicos e/ou materiais.

\section{Casas de show e disputas identitárias: gênero e divisões sociais e territoriais}

Percebe-se também, no Brasil, uma formação discursiva em torno do rock que associa o gênero musical a uma visão política conservadora. Posicionamentos de artistas, listas de bandas, reportagens em jornais e discussões em plataformas de redes 
sociais online têm, amiúde, endossado essa perspectiva. Em Salvador, esse discurso também aparece em enunciados de artistas e em textos publicados em blogs. Estreitando o foco para iniciativas em casas de show no Rio Vermelho, entretanto, é possível perceber movimentos e construções de territorialidades instabilizadoras desse enquadramento, que são, com recorrência, apropriadas de maneira essencialista, seja acionando uma suposta raiz revolucionária do rock, seja categorizando o gênero musical como conservador. Não se nega uma possível ligação, até mesmo significativa, de artistas, fãs e críticos de rock aos posicionamentos associados ao conservadorismo e/ou à extrema direita, mas questiona-se a redução (e o quão produtivo é este vínculo) do rock a essas noções.

Outros dois aspectos discutidos, às vezes interrelacionados a essa primeira concepção, é uma relação apontada entre rock, misoginia e machismo - sendo este considerado um gênero predominantemente masculino, o que se evidencia em Salvador na maior presença de homens na formação dos grupos e do público, perceptível nas próprias experiências em apresentações, em fotos (como as do Vacachorro), flyers etc. e a concentração das casas de show na orla e em bairros de classe-média e classe alta, como Barra e Rio Vermelho.

Considerando tais formações discursivas e determinadas estruturações e relações de poder, como a misoginia e as desigualdades sociais e territoriais, são destacados aqui dois espaços e projetos desenvolvidos no Rio Vermelho que, a partir dos enunciados dos organizadores e das descrições nas suas próprias páginas no Facebook, tensionam a circunscrição do rock como conservador, machista e elitizado. São eles o Saco de Vacilo, projeto que promove shows e debates na casa de shows Bardos e Bardos, e o Faça Você Mesma, com atividades semelhantes, mas voltadas às questões de identidade de gênero, no Mercadão.CC.

O projeto Saco de Vacilo, formado por Rodrigo Gagliano, Gabriel Gomes e Eduardo Lima, atua como produtora, site de crítica musical e coletivo político-cultural vinculado ao rock, particularmente ao hardcore, e com atuação em Salvador. Em suas páginas e perfis em sites de redes sociais online, evitam uma apresentação formal, mas, na seção "Sobre" no Facebook, afirmam: "hardcore é política". Fazem atos de rua, debates, festivais, shows, podcasts e reportagens relacionadas ao rock. Os eventos Bate Papo, produzidos pelo coletivo, têm ocorrido regularmente na casa de shows Bardos e Bardos, 
no Rio Vermelho. Vale destacar duas edições com debatedores convidados, que trataram de "machismo e masculinidades" 21 e da "invisibilidade do hardcore da periferia". 0 tema do primeiro evento, que ocorreu no dia 30 de maio de 2019, foi descrito assim na postagem de divulgação:

\begin{abstract}
Em nossa sociedade, a masculinidade, quando exercida a partir de uma matriz cisheteronormativa, é um lugar de privilégios, reforçando um conjunto de práticas e atitudes sexistas que resultam na opressão e discriminação das mulheres, mas também de outros homens [...] (Divulgação do evento nas páginas Saco de Vacilo Org e Bardos e Bardos no Facebook, 2019). ${ }^{22}$
\end{abstract}

É interessante pensar a potencialidade das casas de shows, dos bares e ambientes boêmios, como espaços também de realização de discussões que aliam engajamentos afetivos e identitários ao entretenimento e a organização política à diversão. Ou seja, produzir territorialidades mais abertas a partir da sua ocupação. Desse modo, a proposta de debate em uma casa de shows privada, mas com entrada gratuita, também ganha relevância ao ampliar as possibilidades de funcionalidade desses territórios e de enfrentar temas considerados "sérios" ou mais ligados à Universidade em um espaço cujas principais convenções organizadoras da sociabilidade são a música (no caso aqui, o rock) e a comercialização de bebidas alcoólicas.

Na relação com o gênero musical, instabiliza a sua associação essencializadora com o conservadorismo, ao disputar abertamente, com uma posição colocada, as relações de poder que envolvem questões em torno da masculinidade e da heteronormatividade. Levando em conta as possíveis contradições ligadas ao fato de que os grupos e o público frequentadores da casa de shows (o nome Bardos e Bardos é sintomático) são compostos majoritariamente por homens - como é possível visualizar nas fotos dos eventos em sua página no Facebook -, a iniciativa também ganha força na medida em que põe relevo, de maneira crítica e numa perspectiva questionadora, tais relações de poder associadas ao rock e aos espaços - incluindo o local do evento. Assim, engajamentos e territorialidades afetivas podem contribuir na rearticulação de certas

210 evento teve Eduardo Carvalho como debatedor, apresentado como "mestre em estudos interdisciplinares sobre mulheres, gênero e feminismos pela Ufbalbúrdia e ideólogo de gênero".

22 Disponível em: <www.facebook.com/pg/Sacodevacilo666/posts/>. Acesso em: junho de 2019. 
formações discursivas e relações de poder, a partir dos vínculos entre rock e Rio Vermelho, ajudando a produzir outros contextos.

Já o Bate Papo sobre "A invisibilidade do hardcore da periferia de Salvador", que teve a participação de Wendel Barreto, integrante da banda Agressivos, retomou o debate sobre a maior visibilidade e concentração das casas de show e da cena de rock no Rio Vermelho, o que paradoxalmente passa também pelo discurso de uma suposta falta de lugares para tocar no próprio bairro, em relação aos espaços periféricos.

\begin{abstract}
Salvador [...] é repleta de disparidades e é ilusório achar que na cena hardcore seria diferente. Sempre houve uma certa hipocrisia até, à medida em que se falava em "somos todos iguais" por estarmos na mesma cena, quando na verdade não somos todos e todas iguais, ao contrário, cada pessoa que compõe a cena hardcore, por mais semelhança ideológica que possa ter, tem suas diferenças pessoais, e seu marcadores sociais bem definidos. 0 que acreditamos ser o mais correto é encarar essas diferenças e, ao menos, tentar eliminar possíveis abismos sociais que separam as pessoas. Muitas pessoas resumem a cena hardcore/punk de Salvador à área mais central da cidade, [...] Centro e Rio Vermelho, [...] com uma divulgação relativamente maior e com uma facilidade de mobilidade [...] (Divulgação do evento nas páginas Saco de Vacilo Org e Bardos e Bardos no Facebook, 2019). ${ }^{23}$
\end{abstract}

Chama a atenção que o eixo afetivo dos territórios é convocado no discurso de apresentação do evento em um entrecruzamento das divisões sociais na cidade tanto em uma perspectiva funcional, ou seja, a dificuldade de divulgação e a mobilidade urbana, mas também no nível discursivo de como o hardcore e o punk se associam a esses territórios. Há um engajamento afetivo que articula ambas as dimensões para construir outras maneiras de ocupar os espaços e também formações discursivas sobre os territórios, propondo "encarar" as diferenças e "eliminar possíveis abismos sociais que separam as pessoas", mesmo que enquadrando os sujeitos em "marcadores sociais bem definidos" - o que, em vez de ampliar, restringe a priori as identidades e identificações.

Produzir conjuntura aqui significa pensar quais são as estratégias para desconstruir essas dicotomias e enquadramentos essencializadores e diminuir a força opressora das divisões sem entrar numa lógica de negação do bairro enquanto território afetivo, de pertencimento, do rock em Salvador. Torna-se fundamental, portanto, encontrar maneiras de rearticular, nos e pelos afetos, as circunscrições e

\footnotetext{
${ }^{23}$ Disponível em: <www.facebook.com/pg/Sacodevacilo666/posts/>. Acesso em: junho de 2019. 
essencializações que vinculam um tipo de música a um território e/ou uma classe social (Farias, 2018).

Já o projeto Faça Você Mesma se apresenta como um "festival feminista que propõe a divulgação das produções de mulheres (cis ou trans) do underground Salvador/BA" ${ }^{24}$. As três edições foram realizadas no Mercadão.CC e tiveram na programação shows, rodas de discussão e exibição de produções audiovisuais feitas por mulheres. A primeira ocorreu em parceria com o Festival BigBands, um dos principais (em termos de público e programação) eventos para o rock, que ocorre há mais de 10 anos na cidade. Ou seja, para denunciar práticas opressoras recorrentes no rock (e não só), propõe discussões para a sua reconfiguração dentro de um evento já relevante nesse contexto musical em Salvador.

Tal como o projeto Saco de Vacilo, o Faça Você Mesma alia os shows aos debates sobre questões sociais, especificamente a opressão contra as mulheres. Dialoga com o valor do it yourself do punk, mas atualizando e rearticulando as identidades de gênero convocadas nos diferentes contextos. Ainda que opere na binariedade (homem e mulher, masculino e feminino), tal como o evento que discutiu masculinidades, coloca em destaque que visa incorporar também as produções das mulheres trans. Chama em causa o eixo afetivo das identidades, em articulação com as territorialidades roqueiras construídas no Rio Vermelho, já explicitado na apresentação das artistas debatedoras²5.

Embora focalize os seus objetivos no fortalecimento da presença feminina no underground, revelando um valor de diferenciação em relação à categoria mainstream (nós e eles) que já agrega também um limite de alcance exposto a priori, o projeto se articula com os coletivos Crust or Die, de Salvador, e Mosh Like a Girl, criado em Vitória da Conquista. Participaram da primeira edição bandas e coletivos de diversos estados, como o Girls to the Front, do Ceará, Calcinhas do Metal, do Pará, e Metaleiras Negras, de São Paulo. Na página no Facebook, o Faça Você Mesma compartilha postagens de outras páginas, como União das Mulheres do Underground e Negras no Underground, divulga

\footnotetext{
${ }^{24}$ Disponível em: <facebook.com/facavocemesmafest/>. Acesso em: junho de 2019.

${ }^{25} \mathrm{Na}$ divulgação do evento, destaca-se algumas identidades e identificações das participantes: "Luciana Rangel (Rango Vegan, Colaboradora da cena punk baiana), Nancy Viegas (bandas: Crack e Nancyta e os Grazers), Sista Katia (Gorda, Vegan, Graffiteira e Feminista) Tatiana Trad (Mãe, Produtora musical, musicista e pesquisadora) e Jardelice Santa Isabel (Loja Punks Not Dead, "Pioneira nos anos 80", Professora/Letras, Mãe, Avó e frequentadora da Cena Punk)". Disponível em: <www.facebook.com/Mercadao.CC/posts/1665355663566215/>. Acesso em: junho de 2019.
} 
músicas e videoclipes de artistas e grupos formados por mulheres (não apenas de rock e de Salvador, mas também de outros locais e gêneros musicais), além de entrevistas com bandas feministas.

Assim, as iniciativas do projeto reverberam também entre artistas, fãs, críticos, jornalistas e pesquisadoras. Em resenha do evento publicada no site de música Oganpazan, a colaboradora Nani Coimbra relata a sua experiência no Faça Você Mesma Vol. 1:

[...] o evento Faça Você Mesma Vol. 1 [...] teve como atração principal uma mesa [...] composta por quatro mulheres para falar sobre a [...] mulher na cena underground soteropolitana. Em meio a relatos pessoais, Tatiana Trad, Sista Kátia, Nancy Viegas e Luciana Rangel resgataram momentos em que nem mesmo o underground pôde acolhêlas devidamente. Por quê? Porque esta cena musical é composta, em sua maioria, por homens, e ser mulher no underground é estar duplamente desajustada. Se [...] for negra é como se não existisse, como afirmou [...] Juliana, [...] da página Metaleiras Negras no Facebook, onde [...] pesquisa sobre a presença, ou ausência, de negras e negros no Metal, ao mesmo tempo em que denuncia o progressivo embranquecimento do Rock. Fenômeno muito similar ao que ocorreu com o axé aqui, na terra da "alegria". Ser mulher no underground é lutar duplamente, triplamente, ou ser atravessada por diversas linhas de opressão para afirmar sua identidade. Dureza é ter que enfrentar isso logo na adolescência. Ou talvez [...] seja essa a temporalidade mais conveniente para afirmar e construir aquilo que se pretende ser. [...] mais importante que aceitar uma condição na qual se encontra é necessário entender quem você é e os instrumentos que possui para se modificar ou se afirmar (COIMBRA, 2018). ${ }^{26}$

Ficam nítidas diversas problemáticas discutidas no evento, entre elas as identidades de gênero, étnico-raciais e os mais diversos "desajustamentos" no contexto musical roqueiro em Salvador, a suposta "terra da alegria" que, quando acionada de modo irônico na resenha, também tensiona essa territorialidade diante das mais diversas opressões e contradições. Chama a atenção também que o axé-music é chamado em causa como uma aproximação, como um modo de ver a reprodução de uma prática de opressão étnico-racial que não se explica, por exemplo, no binarismo underground/mainstream.

Ao compartilhar e tornar comum tais questões dentro do Festival BigBands, o Faça Você Mesma ganha força organizadora de afetos e engajamentos para transformações, mesmo que autolimitadas pela própria noção de underground ${ }^{27}$

\footnotetext{
${ }^{26}$ Disponível em: <www.oganpazan.com.br/o-underground-e-a-liberdade-de-ser-quem-somossera/>. Acesso em: junho de 2019.

${ }^{27} \mathrm{O}$ discurso sobre o underground e o mainstream em Salvador remete às diferenciações do rock em relação ao axé-music, sobretudo entre o final dos anos 1980 e primeira década dos 2000, nas quais o segundo era considerado cooptado, com lógicas de produção industriais e sem autencidade. De um ponto
} 
reiterada nos discursos acerca do projeto. Agrega mulheres que viveram diferentes contextos do rock em Salvador e que propõem, a partir de evento no Rio Vermelho, uma organização em rede para reconfigurar práticas opressoras presentes nos espaços do gênero.

Uma das participantes do evento, Jardelice Santa Isabel, em texto lido durante o evento, abordou a sua experiência com o punk e como dona de uma loja voltada para o rock, nos anos 1980, na capital baiana: [...] foi a salvação pra mim, foi a certeza de algo novo surgindo em termos de transformação, de rebeldia, de contestação. [...] estava decepcionada com o movimento estudantil e [...] sindical e vi, no [...] punk, a forma de continuar dizendo algo à sociedade" (Isabel, 2018). Chama a atenção nesse discurso, para além de uma certa nostalgia que manifesta-se como afeto recorrente nos circuitos roqueiros da cidade ("naquela época era assim, o rock fazia isso e aquilo"), é interessante perceber o papel do rock como organizador e mobilizador de engajamentos para contestação e transformação, inclusive como lugar para formação de alianças alternativas a certos tipos de grupos de militância mais tradicionais, como o movimento estudantil e sindical.

Sem deixar de levar em conta a necessidade de problematizar e continuar refletindo mais profundamente sobre os vetores e caminhos de luta para as mudanças sociais mais amplas, destaca-se como a relação entre práticas diversas associadas ao rock no Rio Vermelho, de um show na rua até um evento com o protagonismo das mulheres do underground, passando por um projeto com shows e debates variados, tensiona a formação discursiva que enquadra o rock como conservador, ao trazer questões atuais e ampliar as discussões sobre identidades (apesar das oscilações para visões essencialistas), como foi apontado como objetivo desta análise. Nesses processos, amiúde, são convocados alguns valores (do it yourself, o underground), que, nos modos propostos, reduzem a multiplicidade e o alcance das pautas e perspectivas de luta. Ao mesmo tempo, tais fenômenos adquirem uma potência ao questionar opressões há bastante tempo reiteradas dentro desses contextos.

\section{Considerações finais}

de vista mais amplo, é possível dizer que alude às limitações que Grossberg (1986) aponta sobre a política do punk.

Dossiê Espaço Urbano e Imaginação Cultural - https://revistaecopos.eco.ufrj.br/ 
Na medida em que a produção da realidade (real e contingente) e dos territórios envolve a prática do poder, questionou-se como o rock, por meio dos engajamentos afetivos, pode rearticular certas relações opressoras (controle territorial, desigualdades sociais, práticas sexistas e racistas) ou redutoras ("rock conservador" ou "elitizado") das multiplicidades das identificações e dos modos de vida, a partir dessas três experiências promovidas no bairro do Rio Vermelho, em Salvador. Apesar das oscilações de valores que tangenciam ou promovem essencializações e fechamentos, movimentos de abertura e deslocamento territoriais também são percebidos, relacionados tanto aos espaços públicos, apresentando enfrentamentos de lógicas de controle e disciplinarização, como às casas de shows privadas, onde ocorrem, além das apresentações, debates acerca de temas diversos que envolvem divisões sociais e territoriais, opressões de gênero e étnico-raciais.

Sublinha-se, dessa maneira, a potência da articulação dos afetos e das formações discursivas para a análise dos engajamentos que interrelacionam música e espaços urbanos em práticas culturais e comunicacionais. A reflexão sobre como as disputas afetivas estão configuradas, assim como os valores e as territorialidades acionadas e construídas, torna-se fundamental não apenas por incorporar problemáticas sociais contemporâneas, mas também por voltar o olhar para a construção de contextos mais diversos e emancipadores. Acredita-se, portanto, que continua sendo produtivo compreender como as práticas de rock (e também de outros gêneros musicais), assim como os seus aparatos (discursivos, performáticos), mobilizam alianças afetivas, engajamentos e resistências, mormente em contextos locais e territórios específicos, para mudanças de certas estruturas do poder na vida cotidiana.

\section{Referências bibliográficas}


CARDOSO FILHO, Jorge. Entre Salvador e o Recôncavo baiano: disputas valorativas a partir das banda de Rock Cascadura e Escola Pública. In: FERNANDES, C; HERSCHMANN, M. (ed). Cidades musicais: comunicação, territorialidade e política. Porto Alegre: Sulina, 2018, p. 293-215.

FARIAS, Daniel 0. de. Disputas afetivas políticas em torno do BaianaSystem: gêneros, territórios e experiências no contexto de Salvador-BA. 126 fls. (Monografia). Faculdade de Comunicação, Universidade Federal da Bahia, Salvador, 2018.

FERNANDES, Cíntia. HERSCHMANN, Micael. Um debate relevante envolvendo ideias fora do lugar?. In: FERNANDES, C; HERSCHMANN, M. (ed). Cidades musicais: comunicação, territorialidade e política. Porto Alegre: Sulina, 2018, p. 7-15.

FOUCAULT, Michel. Microfísica do Poder. Rio de Janeiro: Paz e Terra, 2014.

O Corpo Utópico: As Heterotopias. São Paulo, n-1 Edições, 2013.

A Arqueologia do Saber. Rio de Janeiro: Forense: Universitária, 1987.

GUERREIRO, Goli. A trama dos tambores: a música afro-pop de Salvador. 2ª Ed. São Paulo: Editora 34, 2010.

GROSSBERG, Lawrence. Under the Cover of Chaos: Trump and the battle for the American Right. Pluto Press, London, 2018.

Cultural Studies in the Future Tense. Duke Univ. Press, Durham and London, 2010.

Dancing in Spite of Myself: Essays on Popular Culture. Durham/Londres: Duke Univ. Press, 1997.

Is There Rock After Punk?. In: Critical Studies In Mass Comunication, 3:1, ps. 50-74, 1986. Disponível em: <www.tandfonline.com/loi/rcsm19>. Acesso em: jun. de 2019.

Another Boring Day in Paradise: Rock and Roll and the Empowerment of Everyday Life. In: Popular Music, Vol. 4, Performers and Audiences, ps. 225-258. Disponível em: $<w w w . j s t o r . o r g / s t a b l e / 853365>$. Acesso em: mai. de 2018.

HAESBAERT, Rogério. Viver no Limite: território e multi-territorialidade em tempos de insegurança e contenção. Bertrand Brasil, Rio de Janeiro, 2014.

HERSCHMANN, Micael. Cenas, circuitos e territorialidades sônico-musicais. In: JANOTTI JÚNIOR, Jeder. SÁ, Simone (ed). Cenas Musicais. Guararema: Anadarco, 2013.

JANOTTI JÚNIOR, Jeder. Afeto, autenticidade e sociabilidade: uma abordagem do rock como fenômeno cultural. In: GOMES, Itânia M. Mota \& JACOB DE SOUZA, Maria Carmen. Media \& Cultura. Salvador: Edufba, 2003.

Heavy Metal com Dendê: rock pesado e mídia em tempos de globalização. Rio de Janeiro: E-papers, 2004.

MIGUEZ, Paulo. A emergência do Carnaval afro-elétrico empresarial. Texto apresentado no IX Congresso Internacional da BRASA - Brazilian Sudies Association. Tulane University, 
New Orleans, Louisiana 27 a 29 de março de 2008. Disponível em: <www.brasa.org>. Acesso em: fev. de 2018.

MITTELL, Jason. A Cultural Approach to Television Genre Theory. Cinema Journal, v. 40, n. $3,2001$. 